\title{
Cutaneous Maniestations In HIV Positive Paediatric Patients
}

\author{
Kondreddy $B^{1}$, Kuruvila $M^{2}$, Ullal $K R^{3}$, Bhat $K^{4}$
}

${ }^{1}$ Resident, ${ }^{2}$ Professor, ${ }^{3}$ Senior Resident, Department of Dermatology, Venereology and Leprosy, Kasturba Medical College, Mangalore, Manipal University, India; ${ }^{4}$ Professor, Department of Paediatrics, Kasturba Medical College, Mangalore, Manipal University, India

\section{Address for correspondence}

Dr Krithi Raviraj Ullal

Department of Dermatology,

Venereology and leprosy

Kasturba Medical College,

Manipal University, India

Email: krithiullal@gmail.com

\section{Citation}

Kondreddy B, Kuruvila M, Ullal KR, Bhat K. Cutaneous manifestations in HIV positive paediatric patients. NJDVL 2014; 12(1): 14 - 19.

\begin{abstract}
Background: Over the past decade Human Immunodeficiency Virus (HIV) infection has emerged as a major cause of severe illness and death in childhood in the United States and throughout the world. $\mathrm{CD}_{4}$ cell count and $\mathrm{CD}_{4}$ cell percentage are key markers for determining disease progress and the risk for opportunistic infection (OI) in HIV-infected patients.
\end{abstract}

Objectives: This study was carried out to analyze the cutaneous manifestations in HIV positive paediatric patients and to correlate their pattern and severity with $\mathrm{CD}_{4}$ count.

Material and Methods: This was a hospital based study wherein all HIV positive patients in the paediatric age group were screened for cutaneous manifestations over a period of two years, $\mathrm{CD}_{4}$ counts were estimated and their severity and atypical presentations were correlated with the $\mathrm{CD}_{4}$ counts.

Results: Out of the 104 children included in this study, 93 had cutaneous manifestations. Transplacental was the commonest mode of transmission. There was a significant risk of Grade III malnutrition $(p=0.03)$. Dermatological manifestations were present in all with CD4 count less than 200. The highest mean CD4 count was for bacterial infections and the lowest was for oral candidiasis. The mean CD4 count for fungal infection, oral candidiasis and xerosis were statistically significant $(\mathrm{p}=0.001,0.002,0.025$ respectively)

Conclusion: This study shows that the prevalence of mucocutaneous manifestations increases with advanced immunosuppression in pediatric age group and help in early recognition of the infection.

Keywords: Cutaneous manifestations, Paediatric HIV

\section{Introduction}

Despite recent, improved access to antiretroviral treatment (ART) and care in many regions of the world, more than 35 million people now live with HIV/AIDS out of which 3.3 million of them are under the age of 15 years. In 2012, an estimated 2.3 million people were newly infected with HIV wherein 260,000 were under the age of 15 years. ${ }^{1}$ The first case of AIDS in a child was reported to the Centers for Disease Control (CDC) in 1982. Over the past decade, this disease, caused by infection with human immunodeficiency virus
(HIV), has emerged as a major cause of severe illness and death in childhood in the United States and throughout the world. ${ }^{2}$

Cutaneous manifestations of HIV infection in children include a wide variety of infectious, inflammatory disorders and rarely neoplasms. These disorders tend to be more severe, persistent and resistant to treatment. ${ }^{3}$ Majority of children with HIV infection develop some form of mucocutaneous disease during the course of their illness. In some children, cutaneous disease may 


\section{Original Article}

be the presenting symptom of HIV-related illness. ${ }^{4}$ CD4 cell count and CD4 cell percentage are key markers for determining disease progress and the risk for opportunistic infection (OI) in HIVinfected patients. ${ }^{5}$

The present study is aimed to assess the pattern and severity of cutaneous disease in HIV/AIDS children in relation to CD4 count.

\section{Methodology}

The study population included all HIV positive patients in the paediatric age group attending or referred to the Outpatient Department of Dermatology, Kasturba Medical College Attavar and Wenlock District Hospital, Mangalore over a period of 25 months from August 2006 to September 2008. A total of 104 confirmed cases of HIV infection were comprehensively evaluated and screened for cutaneous manifestations after taking an informed consent. A detailed history pertaining to HIV infection, associated systemic complaints, the mode of onset and evolution of lesions were taken. Details of treatment, including ART and prophylaxis for OI were also noted. Routine investigations, blood chemistry, CD4, CD8 counts and CD4:CD8 ratios were estimated. Tzanck smear, $\mathrm{KOH}$ preparation, fungal culture and pus for culture and sensitivity were done when indicated.

All patients were followed up monthly for 6 months for a repeat complete cutaneous and systemic examination.

\section{Results}

A total of 104 patients with HIV infection/AIDS were screened for cutaneous manifestations. Cutaneous manifestations were seen in 93/104 (89.4\%), 68 (65.4\%) patients being males and 36 $(34.6 \%)$ being females (Table 1$)$. The mean age in our study was 8.27 years $\mathrm{SD} \pm 3.4$. In this study, 11 children were asymptomatic (category N), 16 children were in category A, 29 in category $\mathrm{B}$, and 48 in category $\mathrm{C}$ as per $\mathrm{CDC}$ classification.
In $100(96.15 \%)$ the mode of transmission was transplacental. Both the parents were HIV positive in 100/104 (96.15\%). Both parents were HIV negative in $2 / 104(1.9 \%)$ cases who had received blood transfusion for ITP and fracture femur respectively and the HIV status of both parents were not known in $2(1.9 \%)$ cases.

Table 1: Age and sex distribution of the children screened

\begin{tabular}{l|c|c|c}
\hline Age & Males & Females & Total \\
\hline$<5$ & 13 & 5 & $18(17.30 \%)$ \\
$5-8$ & 22 & 13 & $35(33.65 \%)$ \\
$9-12$ & 25 & 15 & $40(38.46 \%)$ \\
$13-18$ & 8 & 3 & $11(10.57 \%)$ \\
Total & $68(65.38 \%)$ & $36(34.62 \%)$ & 104 \\
\hline
\end{tabular}

$40(38.46 \%)$ patients were in the $9-12$ years age group, the youngest patient being 2 years old, while the eldest 13 years (Table 1). Past history of tuberculosis was noted in $36(34.6 \%)$. Pneumocystis jiroveci pneumonia (PCP) was present in $15.4 \%$ and Cryptosporidial diarrhea in 9.6\%. Recurrent scabies and herpes zoster (HZ) were present in $4.8 \%$ and $1.9 \%$ respectively.

Tuberculosis (TB) was the most common opportunistic infection, present in 36 (34.6\%) patients. Commonest form of TB was pulmonary in $28 / 36(77.7 \%)$ patients, followed by lymphadenitis in $8 / 36(22.22 \%)$.

Treatment history revealed $58(55.8 \%)$ patients were on Antiretroviral therapy (ART), 20 (19.2\%) were on anti-TB treatment and $30(28.84 \%)$ were on PCP prophylaxis.

Table 2: Comparison of $\mathrm{CD}_{4}$ counts in patients with and without ART

\begin{tabular}{c|c|c|c}
\hline \multirow{2}{*}{ CD 4 count } & \multicolumn{2}{|c|}{ ART } & \multirow{2}{*}{ Total } \\
\cline { 2 - 3 } & $(+)$ & $(-)$ & \\
\hline$<200$ & $40(68.96 \%)$ & $1(2.38 \%)$ & 41 \\
$200-500$ & $16(27.58 \%)$ & $22(52.3 \%)$ & 38 \\
$>500$ & $2(3.44 \%)$ & $19(45.2 \%)$ & 21 \\
Total & $58(100 \%)$ & $42(100 \%)$ & 100 \\
\hline
\end{tabular}




\section{Original Article}

General physical examination revealed lymphadenopathy in 32(30.76\%) patients, among whom $59.3 \%$ of patients had generalized lymphadenopathy. Only cervical lymph nodes were enlarged in $31.25 \%$ and inguinal nodes were enlarged in $9.37 \%$. Among 19 patients having generalized lymphadenopathy, $12(63.15 \%)$ had CD4 count less than 200. Pallor was present in 41(39.42\%) patients, 21 (51.21\%) had CD4 count less than 200. Clubbing was present in $2(1.9 \%)$ patients, both with CD4 count less than 200 .

Grade I malnutrition was seen in $28.8 \%$ patients, $21.2 \%$ showed Grade II and $18.3 \%$ showed Grade III malnutrition ( $p$ value 0.03 ). In this study, CD4 count was available for 100 patients out of 104 .

Table 3: Anthropometric evaluation for presence of Malnutrition \& Stunting

\begin{tabular}{|c|c|c|c|c|}
\hline 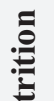 & Grade I & GradeII & Grade III & $\begin{array}{r}\text { Total } \\
\text { n-104 }\end{array}$ \\
\hline$\frac{\Xi}{\Xi}$ & $\begin{array}{c}30 \\
(28.8 \%)\end{array}$ & $\begin{array}{c}22 \\
(21.2 \%)\end{array}$ & $\begin{array}{c}19 \\
(18.32 \%)\end{array}$ & $\begin{array}{c}71 \\
(68.27 \%)\end{array}$ \\
\hline 禹 & $\begin{array}{c}\text { First } \\
\text { degree } \\
32 \\
(30.8 \%)\end{array}$ & $\begin{array}{c}\text { Second } \\
\text { degree } \\
19 \\
(18.3 \%)\end{array}$ & $\begin{array}{c}\text { Third } \\
\text { degree } \\
17 \\
(16.3 \%)\end{array}$ & $\begin{array}{c}\text { Total } \\
\text { n-104 } \\
68 \\
(65.38 \%)\end{array}$ \\
\hline
\end{tabular}

Dermatologic manifestations were present in $89.4 \%$ of patients in this study. All the patients with CD4 count below 200 showed cutaneous manifestations (Table 4).

Table 4: CD4 count in relation with the presence or absence of dermatological manifestation

\begin{tabular}{c|c|c|c}
\hline \multirow{2}{*}{ CD4 count } & \multicolumn{2}{|c|}{ Dermatologic Manifestations } & \multirow{2}{*}{} \\
\cline { 2 - 3 } & Present & Absent & \\
\hline$<200$ & $41(100 \%)$ & $0(0 \%)$ & $41(100 \%)$ \\
$200-500$ & $37(97.37 \%)$ & $1(2.63 \%)$ & $38(100 \%)$ \\
$>500$ & $15(71.43 \%)$ & $6(28.57 \%)$ & $21(100 \%)$ \\
Total & 93 & 7 & 100 \\
\hline
\end{tabular}

A total of $11(10.57 \%)$ patients presented with bacterial infections (Table 5), 7 of whom had folliculitis, of which 2 had CD4 count less than 200. Impetigo was present in 3 patients; one of them had CD4 count less than 200. Ecthyma was present in 1 patient with CD4 count between 200500 .

Viral infections were seen in $23(22.11 \%)$ patients (Table 5). A total of 15(14.4\%) patients had Molluscum Contagiosum (MC), of which $40 \%$ had CD 4 count below 200 and 4 patients had MC on face alone. Two patients had a giant MC surrounded by multiple small lesions on the face. $\mathrm{HZ}$ was present in $3(2.9 \%)$ patients aged 11 and 12 years and verruca vulgaris (VV) in $5(4.8 \%)$ patients.

A total of 36 (34.61\%) patients presented with fungal infections (Table 5). Candidiasis (oral and cutaneous) was present in $29.8 \%$ patients out of whom $18(58.06 \%)$ patients had CD4 count below 200 ( $p$ value 0.024$)$. Tinea versicolor was present in $4(3.8 \%)$ patients ( $p$ value .001$)$ and tinea cruris in $0.9 \%$ patient. Onychomycosis was seen in $4.8 \%$ patients.

Scabies was present in $21.2 \%$ patients of whom $50 \%$ had CD4 count below 200 (Table 5). Recurrent scabies was seen in 5 patients as they were staying together in an ashram.

Among the Non-infectious dermatosis, xerosis was present in $15.4 \%$ and $50 \%$ of them had a CD4 count of less than 200, which was statistically significant ( $p$ value 0.025 ) (Table 5). Seborrheic dermatitis (SD) was present in $7.7 \%$ patients, and $50 \%$ had CD4 count less than 200. Drug reactions were present in $4.8 \%$ patients of whom 3 patients presented with maculopapular rash to cotrimoxazole and 2 patients presented with Steven Johnson Syndrome (SJS) to Nevirapine and Cotrimoxazole. All the 5 patients had CD4 count between 200-500. Papular urticaria was present in $4.8 \%$ patients and $80 \%$ of them had CD4 count less than 200. Acquired ichthyosis 


\section{Original Article}

with rhomboidal scales was present in $1.9 \%$ patients and both of them had CD4 count less than 200. The CD4 count in the single eczema craquele patient was less than 200 .

Oral lesions were present in $28.84 \%$ patients. Pseudomembranous candidiasis was present in 28 (26.9\%) patients, $61 \%$ of them has CD4 count less than 200 and $39 \%$ has CD4 count between 200-500 (p value 0.002) (Table 5).

Nail changes were present in $13.46 \%$ patients. Commonest was melanonychia in $5.8 \%$ patients, followed by onychomycosis in $4.8 \%$ patients. Beaus line was seen in $3(2.9 \%)$ patients.

\section{Mean CD4 count and dermatologic manifestations}

The mean CD4 count in patients with bacterial infections was 398.55 and in patients with oral candidiasis (OC) was 214.9. The mean CD4 count for fungal infections, $\mathrm{OC}$ and xerosis (223.38) was statistically significant.

Table 5: Correlation of Dermatological manifestations with Mean CD4 count

\begin{tabular}{|c|c|c|c|}
\hline $\begin{array}{l}\text { Dermatological } \\
\text { manifestations }\end{array}$ & $\begin{array}{c}\text { Mean } \\
\text { CD4 count }\end{array}$ & $\begin{array}{l}\text { Standard } \\
\text { Deviation } \\
\end{array}$ & $\begin{array}{c}\text { p } \\
\text { Value } \\
\end{array}$ \\
\hline $\begin{array}{l}\text { Bacterial infection } \\
(\mathrm{n}=11)\end{array}$ & 398.55 & 200.5 & NS \\
\hline $\begin{array}{l}\text { Viral infection } \\
(n=23)\end{array}$ & 280.61 & 200.9 & NS \\
\hline $\begin{array}{l}\text { Fungal infection } \\
(n=36)\end{array}$ & 288.64 & 220 & .001 \\
\hline Scabies $(n=22)$ & 297.64 & 189.1 & NS \\
\hline $\begin{array}{l}\text { Seborrheic } \\
\text { dermatitis }(n=8)\end{array}$ & 371.00 & 238.9 & NS \\
\hline Xerosis $(n=16)$ & 223.38 & 118.5 & .025 \\
\hline $\begin{array}{l}\text { Drug reaction } \\
(\mathrm{n}=5)\end{array}$ & 233.40 & 39.469 & NS \\
\hline $\mathrm{OC}(\mathrm{n}=28)$ & 214.9 & 135.9 & .002 \\
\hline $\begin{array}{l}\text { Onychomycosis } \\
(n=5)\end{array}$ & 301.6 & 197 & NS \\
\hline
\end{tabular}

\section{Discussion}

The study group comprised of 68 males and 36 females amongst whom majority (38.46\%) belonged to the age group 9-12 years. The commonest mode of acquiring the infection was transplacental transmission accounting for $96.15 \%$ and $1.9 \%$ by blood transfusion and $1.9 \%$ unknown similar to earlier studies. ${ }^{6}$

The commonest systemic OI was TB accounting for $34.6 \%$ patients. Verghese VP et al in their study accounted for $15.3 \%$ TB of which $14 \%$ had pulmonary and $1.3 \%$ had miliary TB. In this study, pulmonary TB was seen in $77.7 \%$ patients and $22.2 \%$ had TB lymphadenitis. The high percentage may be correlated to the low CD4 count $(<200)$ in $41 \%$ of our patients. ${ }^{6}$ PCP was the other systemic OI, seen in $15.4 \%$ of patients. In a study by Verghese VP et al only $8 \%$ had PCP. Cryptosporidial diarrhea was present in $9.6 \%$ of patients in our study in comparison to $30 \%$ in the same study. ${ }^{6}$

\section{Cutaneous Manifestations}

In this study $89.4 \%$ of patients had cutaneous manifestations. Seoane $\mathrm{R}$ et al reported an incidence of $56 \%$ among 210 patients included in his study. ${ }^{8}$ El Hachem $M$ et al reported an incidence of $97 \%$ among 166 seropositive children. ${ }^{9}$

In this study $10.5 \%$ patients had bacterial infections. Folliculitis was the commonest (63.6\%), followed by impetigo $(27.2 \%)$ and ecthyma (9\%). The incidence of bacterial infection was $18 \%$ in a study by Straka BF et al and $8 \%$ in a study by Lim W et al. ${ }^{10,11}$ The highest mean CD4 count was for bacterial infection (398), and this can be considered as an early cutaneous marker for HIV/AIDS.

Viral infections in this study accounted for 23/104 $(22.11 \%)$. Lim W et al reported an incidence of $38 \%$ in their study among 21 HIV infected patients. ${ }^{11} \mathrm{MC}$ was the commonest viral infection 


\section{Original Article}

seen in $14.4 \%$ patients in this study, similar to other similar studies. ${ }^{8}$ The lesions responded to multiple cryotherapy sessions. HZ was present in $2.8 \%$ and $\mathrm{VV}$ in $4.8 \%$ of patients. This is similar to the other study, where HZ was seen in $2.2 \%$ and VV in $1.1 \%{ }^{6}$ The mean CD4 count for viral infection was 280.61 .

Fungal infections was found in $34.6 \%$ patients. Lim W et al reported an incidence of $69 \%$ in their study among $21 \mathrm{HIV}$ infected children. ${ }^{11}$ The commonest fungal infection in this study was candidiasis (oral and cutaneous) found in 31 (29.8\%) patients. Prose NS reported an incidence of $48 \%$ to $85 \%$ in his study. ${ }^{2}$ Fifty eight percent of patients with candidiasis had CD4 count below 200. The occurrence of candidiasis in patients having CD4 count less than 200 was statistically significant ( $p$ value 0.002 ). OC was seen in $26.9 \%$ and cutaneous candidiasis in $2.8 \%$ similar to other studies. ${ }^{6}$ The mean CD4 count for OC was as low as 214.9 ( $p$ value 0.002) and thus can be considered as a marker for advanced immunosuppression.

Tinea versicolor was seen in $3.8 \%$ patients, and all of them had CD4 count more than 500 compared to an incidence of $2 \%$ in an earlier study of 210 HIV infected children. ${ }^{8}$ The occurrence of tinea versicolor in patients having CD4 count above 500 was statistically significant ( $\mathrm{p}$ value 0.000$)$.

Onychomycosis was seen in $4.8 \%$ patients. All the patients had proximal subungual onychomycosis and had CD4 count between 200500.The mean CD4 count for onychomycosis is 301.6 .

Tinea cruris was seen $0.9 \%$ patient, who had a CD4 count between 200-500.

Scabies was present in $21.2 \%$ patients and $50 \%$ of them had CD4 count less than 200. Five patients had recurrent scabies as they were staying together in a care centre out of which two had extensive lesions which was higher compared to earlier similar studies. ${ }^{6,11}$ The mean CD4 count for scabies was 297.6.

Seborrheic dermatitis was present in $7.7 \%$ patients compared to $20 \%$ and $38 \%$ in earlier studies. ${ }^{8,10}$ The commonest site of involvement was scalp, followed by retroauricular area. CD4 count was less than 200 in $50 \%$ patients. The mean CD4 count for SD was 371 .

Xerosis was seen in $15.4 \%$ patients in our study. Lim $\mathrm{W}$ et $\mathrm{al}^{10}$ reported an incidence of $8 \%$ in their study. Fifty percent of our patients had CD4 count less than 200 ( $\mathrm{p}$ value 0.025 ) which is statistically significant. The mean CD4 count for xerosis was as low as 223.3 and can be considered as another marker of advanced immunosuppression. Acquired ichthyosis was seen in $1.9 \%$ patients who had CD4 count below 200.

Drug reactions were present in $4.8 \%$ in our study. Three patients presented with maculopapular rash due to co-trimoxazole and 2 patients presented with SJS due to nevirapine and co-trimoxazole. All 5 patients had CD4 count between 200-500 and the mean CD4 count was 233.40. In a study by Lim W et al, $8 \%$ of patients had drug reactions to co-trimoxazole and in a study by Straka BF et al $16 \%$ of 50 patients had drug reactions to cotrimoxazole and nevirapine..$^{10,13}$

Papular urticaria was present in $4.8 \%$ patients and $80 \%$ of them had CD4 count less than 200 which was lower compared to other similar study. ${ }^{6}$

\section{CD4 count and dermatologic manifestations}

Dermatologic manifestations were present in all 41 the patients with CD4 count below 200 and in $35.5 \%$ of patients with CD4 count between 200-500. Dermatologic manifestations were present only in $14.4 \%$ of patients with CD4 count above 500. This shows that the prevalence of 


\section{Original Article}

mucocutaneous disease increases with decreasing CD4 count. In a study by Wananukal $\mathrm{S}$ et al, prevalence of mucocutaneous disease in the groups that had severe, moderate and no evidence of immunosuppression was found to be $62 \%$, $43 \%$ and $20 \%$ respectively. ${ }^{12}$

\section{Conclusion}

The highest mean CD4 count was for bacterial infection. The mean CD4 count for xerosis ( $p$ value 0.025$)$ and $\mathrm{OC}(\mathrm{p}$ value 0.002 ) was the lowest. So, these two can be considered as markers

\section{References}

1. url: http://www.amfar.org/about-hiv-and-aids/factsand-stats/statistics--worldwide/ accessed on $19 / 12 / 2013$

2. Prose NS. Mucocutaneous disease in pediatric human immunodefiency virus infection. Pediatr Clin North Am 1991; 38: 977-90.

3. Pizzo PA, Wifret CM. Pediatric AIDS: The challenge of HIV-infection in infants, children and adolescent. $2^{\text {nd }}$ ed. Williams and Wilkins; 1991: 373 .

4. Prose NS. AIDS and the dermatologist: A perspective. Arch Dermatol 1989; 125: 1700-2.

5. Goldstein B, Berman B, Sukenik E, Frankel SJ. Correlation of skin disorders with CD4 lymphocyte counts in patients with HIV/AIDS. J Am Acad Dermatol 1997; 36: 262-4.

6. Verghese VP, Cherian T, Cherian AJ, Babu PG, John TJ, Kirubakaran $\mathrm{C}$ et al. Clinical manifestations of HIV-1 infection. Indian Pediatr 2002; 39: 57-63.

7. Lodha R, Upadhyay A, Kapoor V, Kabra SK. Clinical profile and natural history of children with HIV infection. Indian J Pediatr 2006; 73: 201-4. of advanced immunosuppression. Thus this study shows that the prevalence of mucocutaneous manifestations increases with advanced immunosuppression in pediatric age group and help in early recognition of the infection.

Acknowledgement: I would like to acknowledge Dr B Unnikrishnan, Professor and Head of the Department of Community Medicine, Kasturba Medical College, Mangalore for the statistical analysis of the study data.

8. Seoane RE, Bellon JM, Gurbindo D, MunozFernandez MA. Role of antiretroviral therapies in mucocutaneous manifestations in HIV-infected children over a period of two decades. Br J Dermatol 2005; 153: 382-9.

9. El Hachem M, Bernardi S, Pianosi G, Krzysztofiak A, Livadiotti S, Gattinara GC. Mucocutaneous manifestations in children with HIV infection and AIDS. Pediatr Dermatol 1998; 15: 429-34.

10. Straka BF, Whitaker DL, Morrison SH, Oleske JM, Grant-Kels JM. Cutaneous manifestations of the acquired immunodeficiency syndrome in children. J Am Acad Dermatol 1988; 18: 1089102.

11. Lim W, Sadick N, Gupta A, Kaplan M, Pahwa S. Skin diseases in children with HIV infection and their association with degree of immunosuppression. Int J Dermatol 1990; 29: 2430 .

12. Wananukul S, Deekajomdech T, Panchareon C, Thisyakorn U. Mucocutaneous findings in pediatric AIDS, related to degree of immunosuppression. Pediatr Dermatol 2003; 20: 289-94. 